\title{
O exame Celpe-Bras e o ensino de português em um curso para candidatos ao PEC-G: mecanismo de política linguística em ação ${ }^{1}$
}

\author{
Cynthia Israelly Barbalho Dionísio* \\ Socorro Cláudia Tavares de Sousa**
}

Resumo

O objetivo do artigo é discutir como o exame Celpe-Bras atua como mecanismo de política linguística para professoras de um curso de português para candidatos ao Programa de Estudantes-Convênio de Graduação (PEC-G). A noção teórica de mecanismos de política linguística de Shohamy (2006; 2007; 2009) embasa a discussão dos dados gerados em entrevistas semiestruturadas. A análise da materialidade textual baseou-se na análise do conteúdo temático, da seleção lexical e dos elementos argumentativos segundo Koch (2000; 2011). A conclusão é que o Celpe-Bras atua como mecanismo de política linguística para as professoras ao transformar ideologias em práticas de ensino do que (conteúdo) e como (metodologia) ensinar. Especificamente, o exame atua sobre três eixos da prática docente: no planejamento de aulas, na metodologia de ministração de aulas e na avaliação de produções textuais dos alunos. A política linguística oficial do PEC-G estabelece o Celpe-Bras como requisito para o ingresso em Instituições de Ensino Superior (IES) brasileiras, mas não dispõe sobre currículo, formação de professores, material didático ou outros

\footnotetext{
1 Este artigo deriva de recorte de dissertação de Cynthia Israelly Barbalho Dionísio. O mestrado foi auxiliado por bolsa concedida pela Coordenação de Aperfeiçoamento de Pessoal de Nível Superior (Capes/MEC).

* Universidade Federal da Paraíba (UFPB). Doutoranda em Linguística pela Universidade Federal da Paraíba (Proling/UFPB). Mestra em Linguística (Proling/UFPB). Orcid: https://orcid.org/0000-0001-8666-1122.

** Universidade Federal da Paraíba (UFPB). Doutora em Linguística pela Universidade Federal do Ceará (UFC). Professora do Departamento de Língua Portuguesa e Linguística (DLPL) e do Programa de Pós-Graduação em Linguística (Proling) da Universidade Federal da Paraíba (UFPB). Líder do Núcleo de Estudos em Política e Planejamento Linguístico (Nepel). Orcid: http://orcid.org/0000-0002-0514-9264.
} 
aspectos do ensino. Há prerrogativas e encargos decorrentes da atuação em contexto pautado por um exame de alta relevância, como é o Celpe-Bras para os participantes. Os programas de ensino e os próprios professores gozam de um alto grau de liberdade para criar políticas linguísticas locais visando a endereçar os pontos não cobertos por disposições oficiais ou superiores. Ao mesmo tempo, devem lidar com um possível clima de conflito emergente entre diversas ideologias e práticas quanto ao exame, decorrente da própria liberdade de criação de políticas linguísticas locais responsivas ao contexto.

Palavras-chave: Celpe-Bras. PEC-G. Mecanismo. Política linguística. Português para falantes de outras línguas.

\section{The Celpe-Bras proficiency test and the teaching of Portuguese to candidates to the Student Program-Undergraduate Convention (PEC-G): language policy mechanism in action}

\section{Abstract}

This article aims to discuss how the Celpe-Bras exam acts as a language policy mechanism for teachers of a Portuguese language course for applicants to the Student ProgramUndergraduate Convention (PEC-G). Shohamy's (2006; 2007 ; 2009) theoretical notion of language policy mechanisms supports the discussion of data generated in semi-structured interviews. The analysis of textual materiality was based on the analysis of thematic content, lexical selection and argumentative elements according to Koch (2000; 2011). The conclusion is that Celpe-Bras acts as a language policy 
mechanism for teachers by transforming ideologies into teaching practices of what (content) and how (methodology) to teach. Specifically, the test acts on three axes of teaching practice: in planning classes, in teaching classes and in assessing students' compositions. The PEC-G official language policy establishes Celpe-Bras as a requirement for admission to Brazilian higher education institutions. However, it does not provide guidelines for curriculum, teacher training, teaching material or other aspects of education. There are prerogatives and charges arising from being in a context guided by a highly relevant exam, as is the Celpe-Bras for the participants. Teaching programs and teachers themselves enjoy a high degree of agency to create local language policies aimed at addressing points not covered by official or higher provisions. At the same time, they must deal with a possible climate of conflict emerging because of diverse ideologies and practices regarding the exam, as a result of the freedom to create local language policies responsive to the context.

Keywords: Celpe-Bras. PEC-G. Mechanism. Language policy. Portuguese to speakers of other languages.

Recebido em: 04/03/2021 // Aceito em: 27/03/2021. 


\section{Introdução}

O Certificado de Proficiência em Língua Portuguesa para Estrangeiros (Celpe-Bras) é um dos requisitos para o ingresso de alunos estrangeiros em Instituições de Ensino Superior (IES) brasileiras através do Programa de Estudantes-Convênio de Graduação (PEC-G). Embora a maioria dos estudantes vinculados ao convênio atualmente provenha de países africanos (BRASIL, 2020a; 2020b), o PEC-G oferta vagas em cursos de graduação para alunos da África, América Latina, Caribe, Ásia e Europa (BRASIL, 2020b). Os países contemplados são considerados em desenvolvimento, de acordo com a configuração atual do programa ligada à cooperação internacional Sul-Sul na educação superior.

As regras do PEC-G preveem que os candidatos oriundos de países em que não há Postos Aplicadores do Celpe-Bras têm direito a participar como alunos de cursos de português ofertados por algumas IES brasileiras com o objetivo de prepará-los para o exame. Esses estudantes somente passam a estar vinculados integralmente ao PEC-G depois de obterem a certificação no exame de proficiência, que só pode ser realizado uma única vez. Nesse caso, tornam-se aptos a ingressar no ensino superior brasileiro pelas regras do programa; em caso negativo, devem retornar aos seus países de origem, sendo-lhes negada uma segunda tentativa de ingresso no convênio (BRASIL, 2013a).

Considerando a relação entre o exame e o programa, neste artigo, discutimos como o Celpe-Bras atua como mecanismo de política linguística para professoras de um curso de português para candidatos ao PEC-G. Utilizamos a noção teórica de mecanismo de política linguística de Shohamy 
(2006; 2007; 2009) para compreender a influência do exame no discurso das professoras sobre as suas práticas de ensino. Para tanto, analisamos entrevistas semiestruturadas de acordo com a análise do conteúdo temático, da seleção lexical e dos elementos argumentativos, segundo Koch $(2000 ; 2011)$.

$\mathrm{O}$ artigo soma-se à crescente literatura sobre os aspectos político-linguísticos do convênio, a exemplo de Correa (2010), Diniz e Bizon (2015), Miranda (2018) e Dionísio (2020a; 2020b). Contudo, preenche uma lacuna ainda não explorada por esses trabalhos, a saber: o enfoque na visão dos próprios professores sobre como o exame orienta suas práticas de ensino para o referido grupo, orientado por fundamentos teóricos da Política Linguística. Partindo de outras perspectivas teóricas, os trabalhos de Rodrigues (2006) e Azeredo (2012) buscaram, de formas distintas, refletir sobre a proposta comunicativa do Celpe-Bras e fornecer subsídios para professores de português atuantes na preparação para esse exame. Contudo, ambas as autoras analisaram a relação entre o exame e a docência guiadas pela noção teórica do efeito retroativo do teste nas práticas e discursos dos professores.

Excluindo-se esta introdução, o artigo é organizado em quatro seções. A primeira discute o papel dos testes como mecanismos de política linguística e caracteriza o exame Celpe-Bras e o convênio PEC-G. A segunda seção descreve a metodologia da pesquisa, e a terceira discute os textos-discursos das professoras para candidatos ao convênio sob a ótica da noção de mecanismo de política linguística representado pelo CelpeBras. Finalmente, a última seção tece algumas considerações finais, sintetizando e expandindo as conclusões do estudo. 


\section{Testes de língua como mecanismo de política linguística: o caso Celpe-Bras e PEC-G}

Para compreendermos os testes de língua como mecanismos de política linguística, faz-se necessário esclarecer que a visão de política linguística de Shohamy (2006; 2007; 2009) se caracteriza como expandida. Para a autora, não há apenas políticas explícitas, mas também implícitas. Estas, por sua vez, não estão declaradas em documentos oficiais, como leis, e podem ser examinadas a partir de um conjunto de políticas linguísticas de facto. Nessa perspectiva, os mecanismos de política linguística, segundo Shohamy (2006), são dispositivos explícitos ou implícitos que permitem a criação, a reprodução e a modificação de dada política linguística. Essas ferramentas, termo também utilizado pela autora, funcionam como canal de transformação de ideologias em práticas linguísticas e vice-versa. Shohamy (2006) apresenta os seguintes mecanismos de política linguística: i) regras e normas; ii) educação linguística; iii) testes de língua; iv) linguagem no espaço público; v) ideologia, mitos, propaganda e coerção. Dados os nossos propósitos neste artigo, doravante concentramos a nossa reflexão em torno da categoria dos "testes de língua". Estes são considerados mecanismos "[...] encobertos, uma vez que o público não tem conhecimento de seus efeitos [...]". (SHOHAMY, 2006, p. 93).

Embora os testes, por sua natureza, integrem a categoria mais ampla de mecanismos de educação linguística, Shohamy (2006) os singulariza como uma categoria distinta desta última. O principal motivo para essa distinção é que, ao mesmo tempo

1 No original: "[...] mechanisms that are considered covert since the public is not aware of their effects [...]" (SHOHAMY, 2006, p. 93). 
em que os testes estão ligados à educação linguística, “[...] eles agem como o mecanismo mais poderoso quando se trata de afetar e manipular os comportamentos linguísticos e os usos de alunos, professores, pais de alunos e a sociedade como um todo". ${ }^{2}$ (SHOHAMY, 2006, p. 93). Assim, a diferenciação dos testes como uma categoria per se se deve ao grande poder desses mecanismos no sentido de estarem incorporados em diferentes esferas de atividade humana, afetando o contexto político, o social e, principalmente, o educacional.

No âmbito político e social, os usos dos testes de língua podem servir para a realização de agendas ocultas, como é o caso de exames vinculados à cidadania que restringem o número de imigrantes em um país e exames que criam discriminação étnica. Shohamy (1998) apresenta alguns exemplos: na Austrália, os testes de língua (Access e Step) foram utilizados como uma barreira para aceitar ou rejeitar refugiados; e, na Letônia, como instrumento para produzir uma unidade nacional de modo que só seria permitida a permanência dos russos no país recémindependente, se obtivessem aprovação em testes de língua. Nesses casos, os testes vão além de mecanismos educacionais, transformando-se em instrumentos que "[...] podem determinar a ordem social". 3 (SHOHAMY, 2006, p. 93).

No contexto educacional, os testes são considerados mais fáceis de implementar do que mudanças de base mais profundas na educação ou na sociedade. O potencial de criarem e fomentarem políticas linguísticas de facto faz com que eles sejam utilizados para redirecionar o ensino-aprendizagem de línguas, definindo que tipo de conhecimentos são exigidos e transmitindo

\footnotetext{
2 No original: "[...] it acts as a most powerful mechanism for affecting and manipulating language behaviours and the use of students, teachers, parents and Society as a whole [...]". (SHOHAMY, 2006, p. 93).

3 No original: "[...] and can determine social order". (SHOHAMY, 2006, p. 93).
} 
uma ideia de "neutralidade" à avaliação. Desse modo, o teste de língua cria uma atmosfera de objetividade, retirando toda visão de subjetividade nas escolhas realizadas pelos elaboradores dos exames sobre o quê e como avaliar (SHOHAMY, 1998).

Investigar os testes como imersos em contextos sociopolíticos pautados em relações de poder é se alinhar ao paradigma crítico de pesquisa, de acordo com Shohamy (1998). Um pressuposto da pesquisa crítica sobre os testes é que o ato de testar não é neutro, mas é simultaneamente um produto e um agente para a consecução de objetivos culturais, sociais, políticos, educacionais e ideológicos mais amplos, com potencial de afetar a vida de indivíduos, principalmente professores e alunos. Outro pressuposto é que os testes carregam visões e objetivos estabelecidos por determinados grupos e constituem ferramentas de poder desses grupos em relação a outros. Por último, os testes legitimam determinadas formas de compreensão do mundo enquanto deslegitimam outras, assim como línguas, variedades, modos de aprender e ensiná-las, dentre outras.

Os testes de língua funcionam como meios para a consecução de objetivos individuais e/ou sociais, podendo ser utilizados para classificar e/ou selecionar pessoas para determinados contextos e/ou funções. Algumas finalidades individuais para a realização de testes podem ser o ingresso no ensino superior, a realização de intercâmbios acadêmicos e/ou profissionais, a inserção no mercado de trabalho e a obtenção de cidadania em um país distinto do país de origem. Essas decisões "individuais", termo aspeado pelo reconhecimento da dificuldade em separar o que é individual do que é social em uma decisão como submeter-se a um teste, também geram repercussões na sociedade. Logo, para além do âmbito individual, as finalidades sociais de um teste 


\section{O exame Celpe-Bras e o ensino de português em um curso para candidatos ao PEC-G: mecanismo de política linguística em ação}

podem incluir o alcance de metas e objetivos governamentais no âmbito da educação e em outros âmbitos também, a avaliação da qualidade do sistema educacional como um todo, assim como a avaliação de estabelecimentos educacionais de maneira específica, dentre outras.

Como visto, os testes de língua podem desempenhar um papel que vai além da diagnose ou da avaliação de examinandos ou de instituições, passando a determinar "[...] objetivos, padrões e responsabilização - todos conceitos importantes no processo educacional, especialmente em um contexto em que não há um currículo nacional". ${ }^{4}$ (SHOHAMY, 1990, p. 385). Na ausência ou debilidade de diretrizes superiores, os testes têm grandes chances de pautarem o currículo, redirecionando conteúdos, metodologias, materiais didáticos, formação de professores e outras dimensões do ensino-aprendizagem. Segundo Shohamy (2006), tais dimensões constituem mecanismos de política linguística em si mesmas, mas podem ser consideravelmente afetadas pelo mecanismo dos testes.

Shohamy (2006) indica que o funcionamento relativamente oculto dos testes na modificação de comportamentos e de ideologias linguísticas potencializa a sua atuação como mecanismo de política linguística. Segundo a autora, “[...] o próprio ato de testar já veicula uma mensagem em relação à importância de determinadas línguas em relação a outras". 5 (SHOHAMY, 2006, p. 94). Nesse sentido, eles contribuem para reforçar o prestígio e o status da língua objeto de testagem. A criação do Celpe-Bras pelo governo veicula uma mensagem sobre qual língua tem status no ensino superior nacional: o português brasileiro.

\footnotetext{
4 No original: "goals, standards, and accountability-all important concepts in the process of education, especially in a context where there is no national curriculum". (SHOHAMY, 1990, p. 385).

5 No original: "[...] even the act of testing itself already provides a message as to the importance of certain languages over others". (SHOHAMY, 2006, p. 94).
} 
Finalmente, segundo Shohamy (2006), a modificação dos comportamentos de professores, alunos e demais envolvidos com a situação de testagem não é apenas um "efeito colateral" dos testes. Ao contrário, trata-se da principal função deles, uma vez que os elaboradores geralmente confiam de antemão na capacidade dos testes de promoverem comportamentos considerados desejáveis em um determinado contexto. Em suas palavras, "[...] tomadores de decisão estavam totalmente cientes dos efeitos dos testes na imposição de políticas linguísticas". ${ }^{6}$ (SHOHAMY, 2006, p. 94). Corroborando a afirmação da autora, a modificação de práticas de ensino pelos professores de português para falantes de outras línguas (PFOL) foi um dos principais objetivos que resultaram na implementação do exame Celpe-Bras no Brasil, o qual, desde 1998, atua como um mecanismo de política linguística para candidatos ao convênio PEC-G.

O Celpe-Bras continua sendo o único exame de proficiência em língua portuguesa para estrangeiros reconhecido oficialmente pelo Estado brasileiro ${ }^{7}$ e, portanto, única via admitida para a comprovação da proficiência de candidatos ao PEC-G. Inicialmente, a certificação no exame era demandada apenas para candidatos provenientes de países não vinculados à lusofonia. Excluíam-se da necessidade de certificação, desse modo, os candidatos oriundos dos Países Africanos de Língua Oficial

6 No original: “[...] decision makers were totally aware of the effects of tests in imposing language policies". (SHOHAMY, 2006, p. 94).

7 O reconhecimento do Celpe-Bras como única maneira de comprovar a proficiência de estrangeiros na língua portuguesa para o Estado brasileiro foi alterado pela Portaria Interministerial n ${ }^{\circ} 16$, de 3 de outubro de 2018, expedida pelo Ministério da Justiça. Embora restrinja-se ao processo de reconhecimento e de naturalização de pessoas na condição de apátrida, o documento passou a permitir também o aceite pelo Estado brasileiro de outras formas de comprovação da proficiência no idioma, tais como a conclusão de curso do idioma direcionado a imigrantes realizado em instituição de ensino superior reconhecida pelo Ministério da Educação e a aprovação em avaliação da capacidade de comunicação em língua portuguesa aplicado por instituição de ensino superior reconhecida pelo mesmo órgão na qual seja oferecido o referido curso, dentre outras possibilidades. Disponível em: <https:/www.in.gov.br/web/guest/materia/-/asset_publisher/Kujrw0TZC2Mb/content/id/43885878/do1-2018-10-04portaria-interministerial-n-16-de-3-de-outubro-de-2018-43885761>. Acesso em: 6 dez. 2020. 
Portuguesa (Palop) (BRASIL, 1998). Contudo, desde o Decreto $n^{0}$ 7.948, de 12 de março de 2013, a exigência de certificação no teste foi estendida a todos os estrangeiros pleiteantes a uma vaga no PEC-G, inclusive àqueles provenientes dos Palop ${ }^{8}$ (BRASIL, 2013a).

De acordo com o Decreto de 2013, candidatos ao PEC-G oriundos de países que não dispõem de Postos Aplicadores do Celpe-Bras podem realizá-lo uma única vez no Brasil, após finalizarem curso de língua portuguesa ofertado em IES credenciadas. (BRASIL, 2013a). Tais cursos são ministrados em caráter de extensão e possuem configurações diversas a depender da instituição. Em comum, porém, compartilham o objetivo de preparar os alunos para obterem a certificação no Celpe-Bras, conforme disposto no referido decreto.

O construto teórico que embasa o exame Celpe-Bras compreende a língua como um sistema integrado e holístico, cujo código só produz sentidos em situações reais de comunicação (SCARAMUCCI, 1995). Assim, a competência estrutural na língua é integrada a uma competência maior, comunicativa, que contempla a sintonia entre o uso linguístico e o contexto imediato e sociocultural. (SCARAMUCCI, 1999). De acordo com Schlatter et al. (2009), a visão de desenvolvimento da linguagem subjacente ao exame é vygotskiana, ou seja, concebe a aprendizagem e o desenvolvimento humano como vinculados à prática social.

Em virtude de tal fundamentação teórica, o construto do Celpe-Bras é operacionalizado a partir de tarefas, isto é, ações de linguagem dotadas de propósito comunicativo, com usos semelhantes aos da vida real, formuladas combase na apresentação

8 Para uma problematização da exigência de certificação no Celpe-Bras para candidatos ao PEC-G oriundos dos Palop, cf. Diniz e Bizon (2015). 
de textos autênticos e de circulação ampla na sociedade. Tais textos são contextualizados e apresentados preferencialmente de maneira integral, evitando-se recorrer a trechos avulsos para apresentação aos examinandos (SCARAMUCCI, 1999).

A parte escrita do exame é composta por quatro tarefas, realizadas com base em um vídeo, um áudio e dois textos escritos e dura três horas. A parte oral, por sua vez, constitui-se em uma conversa de 20 minutos na presença de dois avaliadores: um interlocutor e um observador. A parte inicial da conversa acontece com base em informações gerais do participante fornecidas no ato de inscrição no exame, já a maior parte acontece com base em temas propostos a partir da apresentação de diversos gêneros textuais multimodais (como capas de revista, cartuns, etc.). (BRASIL, 2019).

O Celpe-Bras busca realizar uma avaliação qualitativa e global, portanto, sistêmica, da proficiência, cujos resultados fundamentam-se em critérios qualitativos e holísticos, formalizados através de descritores de competência e desempenho. $\mathrm{O}$ exame prevê quatro níveis de certificação: Intermediário, Intermediário Superior, Avançado e Avançado Superior (BRASIL, 2015). Na parte escrita, avalia-se a adequação contextual, a adequação discursiva e a adequação linguística. $\mathrm{Na}$ parte oral, a compreensão, a competência interacional, a fluência, a adequação lexical, a adequação gramatical e a pronúncia.

Desde o início, as publicações de membros integrantes da Comissão Elaboradora do Celpe-Bras indicam o desejo de que o teste não só servisse para avaliar a proficiência linguística dos examinandos, mas também para gerar mudanças no ensino de português para estrangeiros (SCARAMUCCI, 1995; 1999; SCHLATTER, 1999; CUNHA; SANTOS, 1999). Schlatter 
(1999, p. 104), por exemplo, afirma:

Os critérios e os princípios em que se apoia [o exame] terão efeito sobre os sistemas de ensino de língua portuguesa, por um lado harmonizando-os e por outro trazendo-os para uma linha didática mais de acordo com novas realidades.

A modificação almejada seria a transição de um ensino de língua mais formalista para um mais comunicativo, que privilegiasse os usos da língua em contextos reais de comunicação. Nesse sentido, pretende-se com o Celpe-Bras modificar as práticas de ensino de língua, ou seja, criar políticas linguísticas de facto (SHOHAMY, 2006; 2007).

A consciência do poder da implementação do Celpe-Bras na reformulação do ensino de língua portuguesa para estrangeiros também aparece em Scaramucci:

[...] sabemos que introduzir mudanças nesses contextos envolve dificuldades, uma vez que dependem, em grande parte, daqueles diretamente envolvidos nesse processo. Uma maneira de viabilizar tais mudanças seria mediante uma ação direta no processo, promovendo a reciclagem de professores, a produção de materiais didáticos, entre outros recursos. Entretanto, estamos conscientes de que essas transformações são, em geral, lentas, ainda mais se considerarmos que os contextos de ensino de português não se limitam a contextos nacionais, mas também incluem contextos internacionais. Uma maneira indireta, a médio prazo, mas eficiente, seria, portanto, a introdução de um exame que viria a definir não apenas conteúdos e objetivos, mas, principalmente, princípios, fazendo com que o ensino venha, eventualmente, a se adaptar a eles. (SCARAMUCCI, 1999, p. 107, grifos nossos).

Tais mudanças têm maior probabilidade de se tornarem realidade quando o teste de língua em foco se configura como um 
mecanismo de política linguística para os principais envolvidos. Em outras palavras, o teste alcança legitimidade e força para transformar ideologias (de língua, ensino e aprendizagem, por exemplo) em práticas (de ensino-aprendizagem) para professores e estudantes. Até chegar aos alunos, porém, há toda uma interpretação das ideologias do teste e a sua transformação em práticas de ensino pelos professores envolvidos com o contexto de testagem. Nesse caso, o PEC-G se mostra um "laboratório" por excelência, dado que o Celpe-Bras se coloca como uma "ponte" entre o retorno dos candidatos aos países de origem e o ingresso efetivo em cursos de graduação brasileiros. Isso porque o poder dos testes os torna capazes de “[...] cria[r] vencedores e perdedores, sucessos e fracassos, rejeições e aceitações". ${ }^{9}$ (SHOHAMY, 2006, p. 103). Por isso, eles funcionam como "ferramentas disciplinares", no sentido de que tanto o comportamento individual daqueles que a eles se submetem quanto o das instituições educacionais são afetados pelos seus resultados.

\section{Metodologia $^{10}$}

O estudo tem abordagem qualitativa e cunho interpretativista (LIN, 2015), visto que buscamos descrever a perspectiva das professoras sobre a influência do Celpe-Bras nas suas práticas de ensino. O método de geração de dados foi a realização de entrevistas semiestruturadas com três professoras bolsistas vinculadas a um programa de extensão de ensino de PFOL ofertado por uma universidade federal brasileira. Para preservar

\footnotetext{
9 No original: "[...] they create winners and losers; successes and failures, rejections and acceptances". (SHOHAMY, 2006, p. 103).

10 A pesquisa foi aprovada pelo Comitê de Ética em Pesquisa com o Protocolo n ${ }^{\circ}$ 0321/16. CAAE: 55777116.4.0000.5188.
} 
as suas identidades, as professoras são denominadas de acordo com pseudônimos escolhidos por elas para identificação na pesquisa. No período das entrevistas, o programa contava com uma turma intitulada "Curso Intensivo de Português", composta por 20 candidatos ao PEC-G, dos quais 17 eram oriundos de países africanos e três da América Latina, mais precisamente do Haiti. O curso intensivo ocorria de segunda a sexta, no período da tarde, com uma carga horária de 4h/aula diárias (das 14h às $18 \mathrm{~h})$.

As três professoras entrevistadas, à época, cursavam a licenciatura em Letras Português e tinham idades entre 20 e 26 anos. Luna estava no $8^{\circ}$ período da graduação e atuava como professora de PFOL havia dois anos no programa de extensão. Para as turmas do PEC-G, já havia ministrado os cursos de Leitura e de Cultura Brasileira. Durante o período da pesquisa, ministrava o curso Preparatório para o Celpe-Bras. Também relatou uma breve experiência como professora de inglês para brasileiros. Celina estava no $9^{\circ}$ período da graduação e atuava há dois anos e quatro meses como professora de PFOL no programa de extensão. Nos dois anos como professora da turma do PEC-G, ministrou curso de Gramática. Também tinha experiência como professora de Língua Portuguesa em escolas da Educação Básica. Karla estava no $7^{\circ}$ período da licenciatura e atuava como professora de PFOL no programa de extensão há um ano e sete meses. Nas duas turmas do PEC-G que acompanhou, ministrou o curso de Leitura e Produção de Textos. Também tinha experiência no ensino de Língua Portuguesa e de Língua Inglesa para estudantes brasileiros.

As entrevistas com as professoras foram gravadas em áudio e transcritas seguindo os procedimentos da análise da 
conversação propostos por Marcuschi (1991), com algumas adaptações. Na análise, os textos produzidos em situação de entrevista foram entendidos como inseparáveis de relações eminentemente discursivas, constituindo textos-discursos. O paradigma sociocognitivista da Linguística Textual serviu de norte para levar em consideração os sistemas de conhecimento construídos no decorrer do processo de produção e interpretação, bem como o contexto sócio-histórico envolvido nas situações de comunicação (CAVALCANTE; CUSTÓDIO FILHO, 2010). A materialidade textual, isto é, as marcas linguísticas produzidas pelas colaboradoras da pesquisa, foram o ponto de partida para depreender os sentidos construídos por elas na situação de entrevista. O conteúdo temático, a seleção lexical e os elementos argumentativos dos textos-discursos - tais como operadores, marcadores de pressuposição, indicadores modais e de avaliação, conforme Koch $(2000 ; 2011)$ — constituem o foco de análise na materialidade textual, a partir da qual discutimos as maneiras como o Celpe-Bras atua como mecanismo de política linguística para professoras de um curso de português para candidatos ao PEC-G.

\section{0 mecanismo do Celpe-Bras em ação para professoras de português para o PEC-G}

No curso de extensão enfocado, os candidatos ao PEC-G integravam uma turma separada das demais, dado o foco na preparação desses alunos para o Celpe-Bras. Sabendo disso, questionamos como as professoras planejavam as suas aulas de acordo com o objetivo de prepará-los para o exame. A professora Luna assim comentou: 
[...] em preparação para o Celpe-Bras não tem muita criatividade... você dá o gênero textual... depois aplica o Celpe e acabou-se... corrige né? [...] você também não tem muita liberdade de planejar as aulas, né? Então minhas aulas eram muito expositivas... e aí acabava que realmente eu tinha que ser rígida mesmo, vou fazer o quê? [...] porque... você só apresenta os gêneros textuais e depois aplica o Celpe-Bras com eles... é isso que você faz no preparatório $[\ldots] \mathrm{mhm} . .$. eu não criava nada... eu só aplicava outras edições do Celpe-Bras e... acabouse... era a aula... e aí eu apresentava... vários gêneros textuais... que apresentava... que apareciam no Celpe-Bras e... acabou-se... era a minha aula... não tinha muita dificuldade não [...] é muito mais fácil planejar aula... porque não é necessariamente uma aula... é exposição do conteúdo e acabou-se... e aplica o Celpe-Bras. (Luna). ${ }^{11}$

No excerto, o Celpe-Bras é retratado como limitante da liberdade de planejar as aulas e da capacidade de criar da professora. A reiteração da forma verbal "acabou-se" por quatro vezes remete a uma compreensão fatalista da sua prática docente como engessada pelo exame. A solicitação de produção de diversos gêneros textuais pelo exame é interpretada como demandante de um procedimento metodológico definido em sala de aula, conforme indica a modalidade deôntica do verbo “ter" (“eu tinha que ser rígida mesmo... vou fazer o quê?"). Tal procedimento consistia em: i) expor algum gênero textual já abordado no teste; ii) apresentar as características desse gênero textual; e iii) aplicar um simulado de edições anteriores do exame. Contudo, a limitação criativa não é vista apenas de maneira negativa pela professora. Ao contrário, Luna aponta o planejamento e a ministração de aulas com foco exclusivo no teste como mais fáceis do que em outros cenários. $\mathrm{Na}$ verdade,

11 Todos os grifos presentes nos textos-discursos das professoras são de nossa responsabilidade. 
a colaboradora, na argumentação, chega a desconsiderar o procedimento metodológico por ela adotado como um exemplar do gênero "aula", rebaixando-o a uma mera "exposição de conteúdo".

A professora Karla corrobora o alinhamento de sua prática docente de planejamento e metodologia de aula aos pressupostos do Celpe-Bras, assim como o faz Luna. Contudo, diferentemente desta, Karla demonstra adesão ao teste no plano das ideias:

[...] nas minhas aulas... leitura e produção textual né? éh... eu incentivo a eles lerem... lerem muito visto que no Celpe-Bras, né? Eles precisam... éh... fazer qua/ quatro textos, né? E... assim eles têm que no final ter um bom domínio da língua... então a gente já tem que começar inicialmente a... a dar sugestões de leituras... a... ajudá-los, né? No... nas produções textuais no caso a gente tem que trabalhar, né, diversos gêneros textuais... sempre tudo voltado assim principalmente pra o Celpe-Bras... os gêneros que mais caem no Celpe-Bras é o que a gente tenta.... prepará-los... pra eles fazerem essa prova... porque nós sabemos, né, que essa prova é... é de suma importância pra eles porque vai decidir, né, o destino... se eles vão poder continuar aqui no Brasil... fazer uma graduação, né? (Karla).

A professora interpreta a solicitação da produção de gêneros textuais pelo exame como demandante do incentivo à leitura de textos pelos alunos, como fica marcado pelo uso do operador argumentativo "visto que" para introduzir uma oração subordinada denotadora de causa ("visto que no CelpeBras [eles precisam escrever textos], né?"). Conforme relata Karla, o trabalho com a leitura e a produção textual baseado nos gêneros textuais é mandatório não só para ela, mas também para as outras professoras, como revela o uso da voz coletiva e da modalidade deôntica (“a gente tem que trabalhar, né?”) 
e a utilização dos operadores argumentativos intensificadores "sempre" e "principalmente" e do quantificador "tudo" ("sempre tudo voltado assim principalmente para o Celpe-Bras"). A colaboradora indica basear-se na frequência do aparecimento dos gêneros no exame para direcionar suas aulas. Toda a orientação da prática docente das professoras é justificada pela professora Karla como decorrência da alta relevância do Celpe-Bras para os candidatos ao PEC-G, conforme nomenclatura difundida por Scaramucci (2000), sendo capaz de definir os rumos acadêmicos dos estudantes, ao se colocar como porta de entrada na educação superior brasileira. Como visto, o Celpe-Bras define o que é ensinado, pois ambas as professoras exploram os gêneros textuais em suas salas de aula. Inclusive a colaboradora Karla seleciona os que são mais recorrentes, evidenciando o papel dos professores em criar políticas linguísticas de facto que visem a dialogar com o conteúdo do exame (SHOHAMY, 2006; 2009).

A atuação dos alunos na definição do que as professoras deveriam realizar em sua prática docente, de acordo com o que eles entendem ser exigido para um bom desempenho no Celpe-Bras, aparece de maneira recorrente nos excertos das professoras. O excerto a seguir da professora Luna é exemplar dessa compreensão:

[a cobrança vem] principalmente deles [dos alunos]... eles... ahn... eles são muito mais exigentes com as professoras da preparação do Celpe-Bras do que com todas as outras professoras... inclusive tratam as outras professoras como se... como se fossem nada, sabe? Não é como se fosse nada, mas como se fossem menos do que as professoras da preparação... então é um peso muito grande... [...] eles exigem muito mais... e é muito... é muito comum que eles não compareçam às outras aulas pra comparecer só às aulas de preparação... isso acontece muito... é muito comum. (Luna). 
O papel exercido pelos alunos na definição da prática docente, no relato da professora Luna, afetaria a relação interpessoal estabelecida entre eles e as diversas professoras do curso de português para candidatos ao PEC-G. Por um lado, a colaboradora relata sentir-se excessivamente demandada pelos alunos, como reforça a seleção lexical do excerto ("cobrança", “exigentes", "peso", “exigem”). Por outro lado, segundo Luna, a atribuição de prepará-los para o exame geraria uma mudança no status da professora em relação às outras do programa de extensão. Tal distinção se daria quanto ao tratamento, como se observa na gradação argumentativa (as outras professoras seriam tratadas "como se fossem nada" ou "como se fossem menos"), e quanto à assiduidade às aulas pelos alunos, como mostra o operador restritivo destacado ("é muito comum que eles não compareçam às outras aulas pra comparecer só às aulas de preparação"). No curso para o PEC-G ofertado pelo programa de extensão em tela, cada dia da semana é destinado a um foco de aprendizagem e está sob responsabilidade de uma professora diferente. Assim, há turnos dedicados à conversação, à gramática, à leitura e produção textual, à cultura brasileira e, por fim, à preparação para o Celpe-Bras. A compartimentalização didática do ensino de língua portuguesa teria sido interpretada pelos alunos como uma distinção entre aulas que importam e que não importam para a certificação no Celpe-Bras. No relato da professora, os alunos tenderiam a acreditar que as únicas aulas relacionadas diretamente com essa preparação seriam aquelas voltadas para a aplicação de simulados para a prova, o que revela que "os testes serviram então como mediadores para influenciar o comportamento da sala de aula e a pedagogia específica". ${ }^{2}$ (SHOHAMY, 2007, p. 122).

12 No original: "[...] the tests then served as mediators to influence classroom behaviour and specific pedagogy." (SHOHAMY, 2007, p. 122). 
A professora Luna ainda relata como o mecanismo do Celpe-Bras exerce uma pressão constante sobre a sua prática docente:

[...] então acho que a gente a gente pede demais deles... o Celpe-Bras pede demais deles... de um monte de alunos que acabaram de sair do ensino médio... não sabem nem o que é a vida e vêm direto pra outro país, né? [...] o Celpe-Bras pede demais deles... e pra planejar as aulas pra eles... uhn... eu acho que a gente também pede demais deles [...] mas não é tanto a culpa da gente, né, o Celpe-Bras é assim... então não tem o que fazer a não ser que eles mudem. (risos). (Luna).

No excerto, o Celpe-Bras é personificado como agente verbal ("O Celpe-Bras pede demais deles"), e a professora atribuithe a responsabilidade das exigências realizadas pelas professoras (uso da voz coletiva "a gente") aos alunos e avalia as demandas do exame como excessivas (uso do operador argumentativo " $\mathrm{O}$ Celpe-Bras pede demais"). O direcionamento do planejamento das aulas realizado pelo Celpe-Bras é visto de maneira negativa por Luna. A colaboradora utiliza o léxico da "culpa", associado ao campo semântico da religião e do direito, para indicar um conflito quanto à adoção do teste como orientador da sua prática docente. Mais uma vez, Luna reitera uma relação de submissão relutante ao que ela entende ser exigido pelo Celpe-Bras ("não tem o que fazer"), de modo que qualquer mudança na sua prática está condicionada a mudanças no teste, como indicado pelo uso do operador argumentativo (“a não ser que eles mudem”), desencadeada por agentes desconhecidos ou não nomeados por ela ("a não ser que eles mudem”). Nessa perspectiva, "[...] os professores não teriam escolha a não ser preparar seus alunos 
para esse teste"13 (SHOHAMY, 2007, p. 122), constituindo-se, portanto, em "servos do sistema” (SHOHAMY, 2006; 2009), na medida em que buscam reproduzir as "ideologias" dos testes, conforme são interpretadas pelos envolvidos com o exame.

A professora Karla corrobora a atuação dos alunos na orientação da sua prática docente, motivados pela interpretação realizada por eles do que seria solicitado em um exame como o Celpe-Bras, já mencionada pela professora Luna.

[...] eles pedem muito assim... eles ficam muito preocupados com esse exame do Celpe-Bras... então eles querem éh... ficar fazendo muitos simulados do Celpe... mas nós pensamos assim que primeiro eles têm que aprender... ter um domínio maior da língua... pra que a gente possa... éh... fazer uns simulados do CelpeBras... e para o preparatório mesmo do Celpe-Bras... então inicialmente a gente pretende... éh... até julho dar certos conteúdos... claro que ajudando eles a adquirirem a língua e e: também conciliar um pouco por exemplo dos gêneros textuais que mais caem no Celpe-Bras... então a gente já vai preparando eles... só que eles têm que produzirem fazerem produções de textos mas não necessariamente éh... fazerem um simulado como o Celpe-Bras [...] desde que os alunos chegam aqui... eles ficam muito apreensivos quanto a esse exame... por isso que eles ficam pedindo pra fazer o tempo todo simulado como é a prova... éh:: eu até digo pra as meninas que uma pa/se você quiser uma palavrinha mágica na sala de aula fale CelpeBras ((risos)) que todo mundo fica parado olhando assim pra você, paralisado... então eles... já vêm com o Celpe-Bras na mente... éh... e quando é que a gente vai fazer preparatório pra o Celpe-Bras? éh... e essa atividade que você tá passando tem alguma coisa a ver com o Celpe-Bras? Porque eles eles estudam, né, a cultura brasileira... aí às vezes eles perguntam "o que é que isso tem a ver? o que é que a religião tem a ver? o que é que essas festas têm a ver com o Celpe-Bras?" Então

13 No original: “[...] teachers would have no choice but to prepare their students for this test." (SHOHAMY, 2007, p. 122). 
tudo tudo deles é:: voltado para o Celpe-Bras, então por isso que muitas vezes a gente fica... nós ficamos... as professoras ficam muito preocupadas [...] aí a gente também tenta éh... colocar assim atividades e:: todas as coisas que sejam mais voltadas assim pra o Celpe-Bras... preparando eles pra esse exame claro que éh:: nós queremos também ajudá-los, né? Nosso maior intuito é ajudá-los a aprender, né, o idioma a língua portuguesa... mas o Celpe-Bras é uma das coisas que é mais... que são mais preocupantes assim pra eles e acabam passando essa preocupação pra gente. (Karla).

A intervenção dos alunos, para a professora Karla, devese ao próprio uso do Celpe-Bras como mecanismo de política linguística interposto para o preenchimento de vagas em IES brasileiras por candidatos ao PEC-G, que geraria uma ansiedade entre eles ("muito apreensivos", "já vêm [ao Brasil] com o Celpe-Bras na mente", "o Celpe-Bras é uma das coisas [...] mais [...] preocupantes pra eles"). Tal preocupação seria deslocada para as professoras, em um movimento "de baixo para cima" ("eles acabam passando essa preocupação pra gente", "acabam passando essa preocupação pra gente"). Apesar de concordar, em linhas gerais, com a orientação geral dos alunos, a colaboradora se mostra hesitante em assentir sem reservas aos pedidos dos alunos de simular o exame o quanto antes, por acreditar que um desenvolvimento das competências em língua portuguesa, realizado de outras formas, deveria preceder a simulação do teste. Mesmo assim, Karla se apropria do teste como um instrumento de autoridade em sala de aula ("se você quiser uma palavrinha mágica na sala de aula, fale Celpe-Bras") capaz de modificar o comportamento dos alunos ("todo mundo fica parado olhando assim pra você, paralisado"), corroborando Shohamy (2006) quando aponta para o poder dos testes de 
instaurar comportamentos tidos como desejáveis. No caso, em sala de aula, a professora utiliza o poder simbólico do exame para redirecionar a atenção dos alunos.

Segundo Karla, o Celpe-Bras também incide sobre a definição do cronograma de trabalho das professoras. Assim, elas buscam concluir até a metade do ano os aspectos que consideram essenciais na prova, isto é, os gêneros textuais mais recorrentes ("até julho dar certos conteúdos", "conciliar um pouco por exemplo dos gêneros textuais que mais caem no Celpe-Bras"), tendo em vista que a data de aplicação da segunda edição anual do exame cai geralmente em outubro de cada ano.

Para a colaboradora, a interpretação dos alunos em relação à relevância do conhecimento da cultura brasileira para o bom desempenho no Celpe-Bras, traduzida no questionamento "o que isso tem a ver com o Celpe-Bras?", é dissonante quanto aos pressupostos do exame. O Manual do Celpe-Bras de 2013 assim elucida a compreensão de cultura subjacente ao teste:

Com base em uma visão da linguagem como uma ação conjunta de participantes com um propósito social, e considerando língua e cultura como indissociáveis, o conceito de proficiência que fundamenta o Exame consiste no uso adequado da língua para desempenhar ações no mundo. [...] No que se refere à questão cultural, entende-se por cultura as experiências de mundo e práticas compartilhadas pelos membros de uma comunidade. Os indivíduos agem em contexto e, como tal, são influenciados por sua própria biografia, ou seja, pelo contexto social e histórico no qual estão inseridos. Cultura não é vista aqui como uma lista de fatos, autores ou datas importantes, mas como vários processos culturais interrelacionados, tais como formas de interagir em diversas situações e contextos, atribuição de valores, representações de si próprio e do outro, modos de relacionar a interação e a organização cotidiana com sistemas e 

candidatos ao PEC-G: mecanismo de política linguística em ação

processos culturais mais amplos. Cultura não é algo acabado, mas co-construído nas práticas cotidianas de uma comunidade. Levar em conta a cultura brasileira no Exame Celpe-Bras significa, portanto, estar sensibilizado para outros pontos de vista sobre o mundo, considerando-se a situação da interação oral e/ ou escrita. (BRASIL, 2013b, p. 4-5, grifos nossos).

Logo, os elementos mencionados pela professora como questionados pelos alunos quanto à pertinência para uma preparação para o Celpe-Bras (religião e festas) encontram respaldo na compreensão de cultura do construto teórico do exame. Contudo, os questionamentos apontam para a necessidade de explicitar a relação língua-cultura também para os alunos, os quais, de acordo com o relato das professoras, teriam manifestado uma concepção de aprendizagem da língua como treinamento de aspectos formais dos gêneros textuais.

Embora afirme seguir o direcionamento do Celpe-Bras, a professora Karla relata não considerar a sua prática "engessada", como demonstrou a professora Luna anteriormente, dado que a apropriação dos pressupostos teóricos do exame lhe permitiriam elaborar seu próprio material didático:

[...] ano passado éh tinha duas professoras que éh:: estavam mais à frente do preparatório, né, pra o Celpe-Bras.... então elas pegavam provas anteriores e aplicavam, né, com os alunos... éh eu tentava fazer um pouco diferente mas baseado no nesse exame de por exemplo trazer um vídeo... aí tava falando de tecnologia... aí eu tentava elaborar uma provinha que fosse parecida com a do Celpe-Bras. (Karla).

Ao contrastar a sua prática docente com a de outras professoras, Karla relata compreender a preparação ao CelpeBras como indo além da aplicação de simulados, replicando 
provas anteriores. A colaboradora procura produzir seu próprio material com base no formato e nos temas do Celpe-Bras, exemplificando a sua adesão ao teste por meio do uso de vídeo como elemento motivador da produção textual e da abordagem do tema da tecnologia. No relato de Karla, o exame atua como um mecanismo de política linguística na orientação de práticas do que ensinar (gêneros textuais e temas da atualidade) e do como ensinar (através da exibição de vídeos, da aplicação de simulados do teste e de provas semelhantes a ele elaboradas pela professora). Esse dado empírico corrobora a afirmação de que os testes podem definir "[...] o conteúdo e os métodos de ensino que devem ser usados". ${ }^{14}$ (SHOHAMY, 2006, p. 94).

Outra atividade da prática docente das professoras de português para candidatos ao PEC-G relatada por elas como influenciada pelo exame é a avaliação das produções textuais dos alunos. A professora Luna, embora tenha atribuído ao exame Celpe-Bras uma facilidade no ensino de língua portuguesa, nesse contexto, em outro momento, alude à dificuldade de seguir os critérios utilizados por esse teste na avaliação das produções textuais.

[...] eu acho uma pressão grande e também pra que a gente corrija de aCORdo com os parâmetros do INEP... e eles [os alunos] querem que o Celpe-Bras... que a gente aplique as simulações éh... simulações durante as aulas mesmo... eles esperam que esse/ essas simulações sejam assim corrigidas que ne::m no INEP... mas... não tem condições... (tsc) eu ficava me sentindo SUper... ahn... sobrecarregada principalmente pela quantidade de texto que a gente leva pra casa... era tipo dois textos por semana para vi::nte alunos... era vinte? Eu acho que era vinte... então... para vinte alunos... então... não tem condições,

14 No original: "[...] the content and methods of teaching that should be used". (SHOHAMY, 2006, p. 94). 
né?, pra corrigir quarenta textos... toda semana... é muito cansativo. (Luna).

Os parâmetros da avaliação da parte escrita do exame contemplam dois elementos principais: a adequação discursiva e a adequação textual. A adequação discursiva se refere ao reconhecimento do texto produzido como pertencente ao gênero discursivo solicitado, levando-se em consideração o enunciador, o interlocutor, o propósito e as informações aproveitadas do texto-base. Já a adequação textual trata dos aspectos referentes à clareza e à coesão do texto, bem como à relevância das informações inseridas no texto e ao emprego dos itens lexicais e gramaticais para o alcance do propósito da tarefa (BRASIL, 2015).

No excerto anterior da professora Luna, os alunos candidatos ao PEC-G aparecem mais uma vez como os agentes demandantes da adequação da avaliação dos textos (compreendida na perspectiva da "correção") à grade do Celpe-Bras. Os alunos atuariam no sentido de balizar as aulas, solicitando de todas as professoras (uso da voz coletiva "a gente") a realização de "simulações" da prova durante o período das aulas. Contudo, após relatar as demandas dos discentes, Luna demarca a mudança na orientação argumentativa do seu discurso quanto às requisições dos alunos, introduzida pelo operador "mas" ("eles esperam que esse/essas simulações sejam assim corrigidas que ne::m no INEP... mas... não tem condições"). As exigências dos alunos, assim entendidas pela colaboradora, revelam-se uma fonte de angústia para ela, como mostra a seleção lexical, acompanhada por operadores argumentativos intensificadores ("pressão grande", "sobrecarregada", "muito cansativo"). 
A respeito da avaliação dos textos produzidos pelos alunos, a professora Celina relata aderir não só à prática de avaliação, mas também aos pressupostos teóricos do Celpe-Bras:

[...] eu sempre faço [a avaliação] com textos porque eu acho que é a maneira melhor de avaliar apesar de te/ser muito difícil de corrigir, sabe, de colocar a nota... e... quantos erros ele cometeu ali... enfim... eu procuro avaliar a prova dele como um todo... como foi o desempenho dele... e na questão como ele se saiu naquela questão se ele... ah... atendeu ao que eu pedi... que eu prezo muito isso porque eu sei que no CelpeBras eles têm que obedecer ao que foi pedido e às vezes eles erram muito nisso na na na sala de aula. (Celina).

No excerto, a colaboradora demonstra adesão à proposta de avaliação da proficiência baseada na compreensão e produção de textos ("eu sei que no Celpe-Bras eles têm que obedecer ao que foi pedido") de maneira holística ("eu procuro avaliar a prova dele como um todo"). A orientação argumentativa do texto-discurso da professora é predominantemente positiva quanto ao exame; no entanto, a professora Celina também ressalva dificuldade de operacionalizar, na prática docente, os critérios de avaliação do exame, tal como o fez a professora Luna, através da utilização do orientador argumentativo com ideia de oposição e do operador intensificador "muito" para qualificar a dificuldade enfrentada ("apesar de te/ser muito difícil de corrigir, sabe, $[\ldots]$ ]").

\section{Considerações finais}

O objetivo deste artigo foi discutir como o CelpeBras atua como mecanismo de política linguística para 
professoras de um curso de português para candidatos ao

PEC-G. A noção teórica central foi a de mecanismo de política linguística, proposta por Shohamy (2006; 2007; 2009). Os dados motivadores da discussão foram gerados por meio de entrevistas semiestruturadas e analisados com base no conteúdo temático, na seleção lexical e em elementos argumentativos dos textosdiscursos, à luz da proposta de Koch (2000; 2011).

$\mathrm{O}$ relato das professoras indica que o exame Celpe-Bras modifica suas práticas e ideologias sobre o conteúdo (o que ensinar) e a metodologia (como ensinar) de ensino da língua portuguesa no curso voltado para candidatos ao PEC-G. Em virtude da alta relevância desse mecanismo para os envolvidos, cria-se um "currículo" de facto pautado pelos gêneros textuais.

De maneira mais específica, a atuação do Celpe-Bras como mecanismo de política linguística afeta a prática docente em três eixos principais: no planejamento de aulas, na metodologia de ministração e na avaliação das produções textuais dos alunos. Quanto ao planejamento, o mecanismo do Celpe-Bras direciona as professoras a centrarem os seus esforços na assimilação de características de diversos gêneros textuais, de acordo com a recorrência desses gêneros em edições anteriores do teste. Quanto à metodologia de ensino, o Celpe-Bras conduz a um fazer baseado na exposição de características de gêneros textuais, na simulação de edições anteriores e na busca pela elaboração própria de atividades que se aproximem do exame, baseadas na exibição de vídeos e na abordagem de temas da atualidade. Quanto à avaliação das produções textuais dos alunos, as professoras se baseiam na grade de avaliação do Celpe, de modo que estas buscam se adequar a ela, embora salientem a dificuldade de avaliar as produções dos alunos segundo esse parâmetro. 
Marcante nos textos-discursos das professoras é o exercício da agência dos alunos do PEC-G no contexto do programa de extensão em tela. Contrariando a expectativa de que a maior cobrança pela adequação das professoras aos pressupostos do teste se manifestasse de cima para baixo, por exemplo, através da coordenação do curso ou do próprio setor dedicado ao PEC-G na instituição, elas apontam os alunos como principal influência nesse sentido.

A política linguística oficial de ensino de português para candidatos ao PEC-G vigente até o momento, materializada no Decreto de 2013, estabelece o Celpe-Bras como requisito para o acesso desses estudantes a vagas em IES brasileiras (BRASIL, 2013a). Não há outras disposições oficiais referentes ao currículo, à formação de professores, ao material didático ou aos outros aspectos que envolveriam essa política na atualidade. Logo, fica a cargo das instituições e, especificamente, dos próprios programas de ensino de língua alocados em universidades credenciadas para ofertá-los, deliberar localmente a abordagem, as estratégias de formação de professores e a escolha/elaboração de material didático, dentre outros aspectos. Sendo assim, cabe primordialmente aos agentes locais as prerrogativas e os encargos decorrentes da atuação em contexto pautado por um exame de alta relevância como o Celpe-Bras para os participantes. Como prerrogativas, os programas de ensino e os próprios professores gozam de muita liberdade para criar políticas linguísticas de facto, visando a endereçar os pontos não cobertos por disposições oficiais ou superiores. Como encargos, devem lidar com um possível clima de conflito emergente entre diversas ideologias e práticas quanto ao exame, decorrente da própria liberdade de criação de políticas linguísticas locais responsivas ao contexto. 
Nesse sentido, ao desvelarmos o papel do exame CelpeBras como mecanismo de política linguística transformador de ideologias em práticas de ensino para as professoras de português envolvidas em um curso para candidatos ao PEC-G, mostramos que elas visam a "reproduzir" o conhecimento institucionalizado pelo teste. Contudo, esse conhecimento é interpretado por elas de forma distinta do exame. Em outras palavras, de acordo com o construto teórico previsto pelo Celpe-Bras, os gêneros textuais não deveriam ser o foco da aprendizagem da língua, mas resultado da interação genuína em língua portuguesa. No curso, esse conteúdo, ainda de acordo com o relato das colaboradoras, é apresentado de maneira expositiva com base em suas "características" e na perspectiva do "treinamento" dos alunos para submeterem-se ao teste.

A agência das professoras também é destacada nesta pesquisa, pois, ao comprovarmos que o Celpe-Bras é um mecanismo de política linguística e que é interpretado de forma própria por essas agentes, questionamos a influência do exame na promoção das mudanças educacionais pretendidas quando da sua criação. Dessa forma, consideramos que não apenas a criação de um teste é suficiente para alterar o ensino de PFOL, como também a formação de professores que visem a explorar o construto teórico-metodológico do exame e a(s) pedagogia(s) de ensino que atenda(m) a esse construto, seja dentro das licenciaturas em Letras/Português, seja em cursos de extensão, seja em oficinas ou minicursos realizados em eventos científicos, dentre outras possibilidades.

Considerando a área de Política Linguística em que se insere este trabalho, sugerimos a realização de investigações: i) em outros contextos de preparação para o Celpe-Bras, de 
modo a descrever os processos de interpretação e apropriação desse teste pelos professores em suas práticas de ensino, a partir da noção teórica de política linguística como processo (JOHNSON, 2013); ii) em materiais didáticos produzidos pelos professores de PFOL, por editoras, considerando esses materiais como mecanismo de política linguística, conforme fez Oliveira (2019) em livros didáticos de português como língua materna; iii) em textos-discursos de educadores, alunos e pais que estão envolvidos com o exame sobre a valoração do português brasileiro como língua internacional, a partir da dimensão das crenças de Spolsky (2009).

\section{Referências}

AZEREDO, Luciana Aparecida Silva de. Relação poder-saber no/pelo certificado de proficiência em língua portuguesa para estrangeiros e os modos de subjetivação de professores. 2012. 114 f. Dissertação (Mestrado em Linguística Aplicada) Universidade de Taubaté, Taubaté, 2012.

BRASIL. Protocolo de 13 de março de 1998. Protocolo que entre si celebram o Ministério das Relações Exteriores e o Ministério da Educação e do Desporto, para regulamentar o Programa de Estudantes Convênio de Graduação. Brasília, DF, 13 mar. 1998.

BRASIL. Decreto n. 7.948, de 12 de março de 2013. Dispõe sobre o Programa de Estudantes-Convênio de Graduação PEC-G. Brasília, DF, 23 mar. 2013a.

BRASIL. Ministério da Educação. Certificado de proficiência em língua portuguesa para estrangeiros: guia do examinando. Brasília, DF: MEC/INEP, 2013 b. 
O exame Celpe-Bras e o ensino de português em um curso para candidatos ao PEC-G: mecanismo de política linguística em ação

BRASIL. Ministério da Educação. Certificado de proficiência em língua portuguesa para estrangeiros: manual do examinando. Brasília, DF: MEC/Inep, 2015.

BRASIL. Ministério da Educação. Instituto Nacional de Estudos e Pesquisas Anísio Teixeira. Celpe-Bras: cartilha do participante. Brasília, DF, 2019.

BRASIL. Ministério das Relações Exteriores. Divisão de Assuntos Educacionais. Histórico do programa: introdução. 2020a. Disponível em: $<$ http://www.dce.mre.gov.br/PEC/G/ historico/introducao.php>. Acesso em: 28 mar. 2020.

BRASIL. Ministério das Relações Exteriores. Divisão de Assuntos Educacionais. Países participantes. 2020b. Disponível em: $\quad<$ http://www.dce.mre.gov.br/PEC/paises_participantes. php>. Acesso em: 19 mar. 2020.

CAVALCANTE, Mônica Magalhães; CUSTÓDIO FILHO, Valdinar. Revisitando o estatuto do texto. Revista do GELNE, [s. l.], v. 2, p. 56-71, 2010.

CORREA, Djane Antonucci. Política linguística e o curso de licenciatura em Letras: um estudo inicial sobre o PEC-G. Linguagem em Foco, [s. l.], v. 2, n. 2, p. 39-52, 2010.

CUNHA, Maria Jandyra; SANTOS, Percília. O certificado de proficiência em língua portuguesa para estrangeiros (CelpeBras): a possibilidade de um diagnóstico na Universidade de Brasília. In: CUNHA, Maria Jandyra; SANTOS, Percília (org.). Ensino e pesquisa em português para estrangeiros. Brasília: Editora Universidade de Brasília, 1999. p. 113-122.

DINIZ, Leandro Rodrigues Alves; BIZON, Ana Cecília Cossi. Discursos sobre a relação Brasil/África "lusófona" em políticas linguísticas e de cooperação educacional. Língua e Instrumentos Linguísticos, [s. l.], n. 36, jul./dez. 2015.

DIONÍSIO, Cynthia Israelly Barbalho. Crenças sobre o exame Celpe-Bras de agentes envolvidos com o programa de estudantes- 
convênio de graduação (PEC-G). Travessias Interativas, Aracaju, v. 10, p. 120-137, 2020a.

DIONÍSIO, Cynthia Israelly Barbalho. Uma análise documental das políticas linguísticas oficiais para o Programa de EstudantesConvênio de Graduação (PEC-G): olhar para trás para projetar à frente. Horizontes de Linguística Aplicada, [s. l.], Brasília, v. 19, n. 1, p. 73-101, 2020b.

JOHNSON, D. C. Language policy. New York: Palgrave Macmillan, 2013.

$\mathrm{KOCH}$, Ingedore Grunfeld Villaça. A inter-ação pela linguagem. 5. ed. São Paulo: Contexto, 2000.

$\mathrm{KOCH}$, Ingedore Grunfeld Villaça. Argumentação e linguagem. 13. ed. São Paulo: Cortez, 2011.

LIN, A. M. Y. Researcher positionality. In: HULT, F. M.; JOHNSON, D. C. (org.). Research methods in language policy and planning: a pratical guide. UK: Wiley Blackwell, 2015. p. 21-32.

MARCUSCHI, Luiz Antônio. Análise da conversação. São Paulo: Ática, 1991.

MIRANDA, Yara Carolina Campos de. "Pelo mundo": a configuração de uma política linguística no ensino de português como língua adicional em um curso para candidatos ao Programa de Estudantes-Convênio de Graduação (PEC-G). Revista X, Curitiba, v. 3, n. 1, p. 116-140, 2018.

OLIVEIRA, Kátia Cristina de Oliveira. O manual do professor de língua portuguesa como mecanismo de política linguística. Caletroscópio, [s. l.], v. 7, n. especial 1, p. 167-182, 2019. RODRIGUES, Meirélen Salviano Almeida. O exame CelpeBras: reflexões teóricas para o professor de português para falantes de outras línguas. 2006. 119 f. Dissertação (Mestrado em Linguística Aplicada) - Instituto de Estudos da Linguagem, Universidade Estadual de Campinas, Campinas, 2006. 
SCARAMUCCI, Matilde V. Ricardi. O projeto Celpe-Bras no âmbito do Mercosul: contribuições para uma definição de proficiência comunicativa. In: ALMEIDA FILHO, José Carlos Paes. (org.). Português para estrangeiros: interface com o espanhol. Campinas, SP: Pontes, 1995. p. 77-90.

SCARAMUCCI, Matilde V. Ricardi. Celpe-Bras: um exame comunicativo. In: CUNHA, Maria Jandyra; SANTOS, Percília. (org.). Ensino e pesquisa em português para estrangeiros. Brasília: Editora Universidade de Brasília, 1999. p. 105-112.

SCARAMUCCI, Matilde V. Ricardi. Proficiência em LE: considerações terminológicas e conceituais. Trabalhos em Linguística Aplicada, Campinas, v. 36, p. 11-22, jul./dez. 2000. SCHLATTER, Margarete. CELPE-Bras: certificado de língua portuguesa para estrangeiros - breve histórico. In: CUNHA, Maria Jandyra; SANTOS, Percília. (org.). Ensino e pesquisa em português para estrangeiros. Brasília: Editora Universidade de Brasília, 1999. p. 97-104.

SCHLATTER, Margarete et al. Celpe-Bras e Celu: impactos da construção de parâmetros comuns de avaliação de proficiência em português e em espanhol. In: ZOPPI-FONTANA, Mónica Graciela. (org.). O português do Brasil como língua transnacional. Campinas: Editora RG, 2009. p. 95-122.

SHOHAMY, Elana. Language testing priorities: a different perspective. Foreign Language Annals, [s. l.], v. 23, n. 5, oct. 1990.

SHOHAMY, Elana. Critical language testing and beyond. Studies in Educational Evaluation, [s. l.], v. 24, n. 4, p. 331345, 1998.

SHOHAMY, Elana. Language policy: hidden agendas and new approaches. London: Routledge, 2006.

SHOHAMY, Elana. Language tests as language policy tools. Assessment in Education, [s. l.], v. 14, n. 1, p. 117-130, mar. 2007. 
SHOHAMY, Elana. Language teachers as partners in crafting educational language policies? Íkala, revista de language y cultura, [s. l.], v. 14, n. 22, p. 45-67, mayo-ago. 2009.

SPOLSKY, B. Language management. Cambridge: Cambridge University Press, 2009. 